\title{
Coinoculação de Bradyrhizobium japonicum e Azospirillum brasilense em sementes de amendoim de diferentes tamanhos
}

\author{
Elijanara Raissa da Silva'; Josiane Souza Salles', Alan Mario Zuffo ${ }^{1}$, Fábio Steiner \\ ${ }^{1}$ Universidade Estadual de Mato Grosso do Sul - UEMS, Unidade Universitária de Cassilândia, Cassilândia, Mato Grosso do Sul, \\ Brasil. E-mail: raissa@agronoma.eng.br, josi_souzasalles@hotmail.com, alan_zuffo@hotmail.com, steiner@uems.br
}

Recebido: 03/09/2017; Aceito: 29/10/2017.

\section{RESUMO}

O tamanho da semente é um importante indicador físico da qualidade fisiológica das sementes, pois pode afetar a taxa de germinação e o crescimento inicial das plântulas. Neste contexto, o presente estudo teve como objetivo avaliar os efeitos do tamanho das sementes e da inoculação de Bradyrhizobium japonicum e Azospirillum brasilense de forma isolada ou combinada na emergência das plântulas, nodulação das raízes e no crescimento inicial das plantas de amendoim (Arachis hypogaea L., cv. IAC Tatu ST). As plantas foram cultivadas em vasos plásticos de 8,0 L preenchidos com um solo arenoso do Cerrado e mantidas sob condições de casa-de-vegetação. $\mathrm{O}$ delineamento experimental utilizado foi o de blocos ao acaso em esquema fatorial $3 \times 4$ com quatro repetições. Os tratamentos foram constituídos por três tamanho de sementes (pequena, média e grande) e por quatro tratamentos de inoculação: i) controle (sem inoculação); ii) inoculação das sementes com Bradyrhizobium japonicum; iii) inoculação das sementes com Azospirillum brasilense; e, iv) coinoculação das sementes com $B$. japonicum e A. brasilense. Os resultados reportaram que a utilização de sementes grandes melhorou a nodulação das raízes, o crescimento das plantas, o acúmulo e a partição de matéria seca das plantas. Portanto, a implantação da cultura do amendoim deve ser realizada com a utilização de sementes de maior tamanho (grandes), por proporcionar sustentabilidade para o sistema de produção de amendoim, melhorando a fixação biológica de nitrogênio e o crescimento das plantas cultivadas em solos arenosos do Cerrado Sul-mato-grossense. A coinoculação das sementes com B. japonicum e A. brasilense melhorou a nodulação das raízes e a altura das plantas, no entanto, não teve efeito no crescimento, na partição de matéria seca e nos índices morfofisiológicos das plantas de amendoim, quando cultivadas em solos arenosos do Cerrado sob condições controladas.

Palavras-chave: Arachis hypogaea L, inoculação, nodulação, reserva da semente.

\section{Co-inoculation of Bradyrhizobium japonicum and Azospirillum brasilense on peanut seeds of different sizes}

\begin{abstract}
The size of the seed is an important physical indicator of the physiological quality of the seeds, since it can affect the germination rate and initial growth of the seedlings. In this context, the present study had the objective of evaluating the effects of seed size and inoculation of Bradyrhizobium japonicum and Azospirillum brasilense on seedling emergence, root nodulation and early growth of peanut (Arachis hypogaea L., cv. IAC Tatu ST). The plants were grown in $8.0 \mathrm{~L}$ plastic pots filled with sandy soil and kept under greenhouse conditions. The experimental design was a randomized complete block design in a $3 \times 4$ factorial scheme with four replications. The treatments consisted of three seed sizes (small, medium and large) and four inoculation treatments: i) control (without inoculation); ii) seed inoculation with Bradyrhizobium japonicum; iii) seed inoculation with Azospirillum brasilense; and, iv) seed co-inoculation with B. japonicum and A. brasilense. The results reported that the use of large seeds improved root nodulation, plant growth, accumulation and dry matter partition of plants. Therefore, the implantation of the peanut crop should be carried out using larger seeds, as it provides sustainability for the peanut production system, improving the biological nitrogen fixation and growth of the plants in sandy soils. Seed co-inoculation with B. japonicum and A. brasilense improved root nodulation and plant height, however, had no effect on growth, dry matter partition and morphophysiological indexes of peanut plants when grown on sandy soils under controlled conditions.
\end{abstract}

Key words: Arachis hypogaea L, inoculation, nodulation, seed reserve. 


\section{Introdução}

O amendoim (Arachis hypogaea L.) é uma planta leguminosa, herbácea, anual, originária da América do Sul, pertencente à família Fabaceae. A cultura do amendoim é a quarta oleaginosa mais cultivada no mundo, ocupando cerca de 24 milhões de hectares (FAOSTAT, 2017). O cultivo do amendoim é uma excelente alternativa de diversificação para os produtores rurais, pois possui múltiplas utilidades. Possui grande importância no mercado nacional e mundial, sendo que a produção de grãos é destinada, principalmente, para o consumo in natura, e para a produção de óleo e farelo, dentre outros produtos. Atualmente, a ampliação do mercado tendo em vista à produção de biodiesel traz novas e favoráveis perspectivas de ampliação dessas culturas na região do Cerrado Sul-Mato-Grossense.

$\mathrm{O}$ amendoim possui enumeras vantagens quando cultivado em programas de rotação de culturas, pois a cultura tem como característica: ciclo curto, resistência à seca e cultivo totalmente mecanizado, sendo dessa forma muito empregado em áreas de reforma de canaviais e de pastagens (GROTTA et al., 2008). Portanto, a região Leste do Estado de Mato Grosso do Sul possui alto potencial para o cultivo do amendoim, sendo esta atividade uma opção altamente viável para os produtores rurais, uma vez que contribui com a diversificação da produção de alimento e, ao mesmo tempo, com a sustentabilidade da propriedade rural. No entanto, o cultivo do amendoim não tem sido explorado na região Leste do Mato Grosso do Sul, e pouco se conhece a respeito da resposta desta cultura à prática de coinoculação das sementes com diferentes rizobactérias promotoras de crescimento de plantas (RPCP).

$\mathrm{O}$ amendoim por ser uma espécie leguminosa, possui a capacidade de associação com bactérias fixadoras de $\mathrm{N}$ (Bradyrhizobium sp.), o que lhe permite eficiência no processo de absorção desse nutriente. No entanto, a prática de inoculação com Bradyrhizobium (rizóbio) nos cultivos comerciais de amendoim no Brasil não tem sido muito comum, principalmente, devido a ampla faixa de rizóbios nativos presentes nos solos tropicais com capacidade de colonizar as raízes de amendoim (THIES et al., 1991). No entanto, em algumas situações, como em áreas de primeiro cultivo de plantas leguminosas, onde não existem populações consideráveis de rizóbio no solo, a prática de inoculação tem sido recomendada com a finalidade de aumentar o rendimento de grãos da cultura, como reportado por Crusciol e Soratto (2007).

Considerando as limitações da FBN do amendoim inoculado com Bradyrhizobium, a utilização de RPCP, capazes de promover efeito sinergístico na nodulação e no crescimento das plantas, pode representar uma alternativa para maximizar a eficiência da fixação de $\mathrm{N}$ e incrementar a produtividade da cultura. Dentre as rizobactérias utilizadas na inoculação de outras espécies leguminosas, se destacam as bactérias do gênero Azospirillum (CASSÁN et al., 2008; HUNGRIA; NOGUEIRA, 2013). Neste contexto, iniciou-se, nos últimos anos no Brasil, os estudos com coinoculação de Bradyrhizobium sp. e Azospirillum brasilense nas culturas de soja e de feijão, buscando ganhos em nodulação e suprimento de $\mathrm{N}$, e maior produtividade de grãos (HUNGRIA et al., 2013). Nos casos em que se tem utilizado $A$. brasilense em leguminosas, os efeitos benéficos da associação com o Bradyrhizobium se devem, na maior parte, a capacidade que a rizobactéria tem de fixar $\mathrm{N}_{2}$ atmosférico (HUERGO et al., 2008), produzir hormônios vegetais (BOTTINI et al., 1989), aumentar a atividade da enzima nitrato redutase (CASSÁN et al., 2008) e solubilizar fosfato do solo (INAGAKI et al., 2014). Em geral, tem sido relatado que as RPCP beneficiam o crescimento e o desenvolvimento das plantas por uma combinação de todos esses mecanismos (DOBBELAERE et al., 2003). No entanto, não há estudos que comprovam os efeitos benéficos da coinoculação de bactéria dos gêneros Bradyrhizobium e Azospirillum na cultura do amendoim.

Outro fator que pode afetar o crescimento das plantas e a produtividade da cultura do amendoim é o tamanho das sementes utilizadas na semeadura. A semente caracteriza-se como o elemento básico para a formação de um estande adequado e, consequente, pode afetar o desenvolvimento e a produtividade da cultura. O tamanho da semente é um importante indicador físico da qualidade fisiológica das sementes, pois pode afetar a taxa de germinação e o crescimento inicial das plântulas.

Estudos realizados por Carvalho (1972), reportaram que sementes de amendoim maiores são responsáveis por dar origem a plântulas mais vigorosas, sendo que plantas provenientes de sementes pequenas apresentam menor crescimento inicial quando comparadas as plantas oriundas de sementes grandes. Por sua vez, Queiroga et al. (2011) constataram que as sementes a granel e sementes pequenas se destacaram nos testes de germinação e vigor em relação as sementes de maior tamanho, sendo que o tamanho das sementes não influenciou na qualidade fisiológica.

Portanto, apesar do alto potencial de cultivo do amendoim para a região do Cerrado Sul-Matogrossense, há grande deficiência de pesquisas sobre os efeitos promovidos pela coinoculação das sementes com RPCP e a influência do tamanho das sementes no crescimento inicial da cultura na região Leste do Mato Grosso do Sul. Neste sentido, este estudo teve como objetivo avaliar o efeito da coinoculação de Bradyrhizobium japonicum e Azospirillum brasilense 
em sementes de amendoim (Arachis hypogaea L., cv. IAC Tatu ST) de diferentes tamanhos na emergência das plântulas, nodulação e no crescimento inicial das plantas cultivadas em um solo arenoso do Cerrado.

\section{Material e Métodos}

$\mathrm{O}$ experimento foi realizado em casa de vegetação na Estação Experimental Agronômica da Universidade Estadual de Mato Grosso do Sul - UEMS, em Cassilândia, MS (1906'48" de latitude Sul; 51²4'03" de longitude Oeste e altitude média de $470 \mathrm{~m}$ ), no período de dezembro de 2016 a fevereiro de 2017. Foram utilizados vasos plásticos com 8,0 L de capacidade, preenchidos com 7,5 L de solo arenoso peneirado em malha de $5 \mathrm{~mm}$, proveniente da camada superficial de $0,0-0,20 \mathrm{~m}$ de um Neossolo Quartzarênico, apresentando as seguintes características químicas: $\mathrm{pH}$ em $\mathrm{CaCl}_{2}=5,6$, matéria orgânica $=14 \mathrm{~g}$ $\mathrm{dm}^{-3}, \mathrm{P}\left(\right.$ Mehlich-1) $=8,3 \mathrm{mg} \mathrm{dm}^{-3}, \mathrm{~K}=0,07 \mathrm{cmol}_{\mathrm{c}} \mathrm{dm}^{-}$ ${ }^{3}, \mathrm{Ca}^{2+},=2,00 \mathrm{cmol}_{\mathrm{c}} \mathrm{dm}^{-3}, \mathrm{Mg}=0,70 \mathrm{cmol}_{\mathrm{c}} \mathrm{dm}^{-3}, \mathrm{H}+\mathrm{Al}$ $=2,00 \mathrm{cmol}_{\mathrm{c}} \mathrm{dm}^{-3}, \mathrm{CTC}=4,80 \mathrm{cmol}_{\mathrm{c}} \mathrm{dm}^{-3} \mathrm{e} \mathrm{V}=58 \%$. O solo foi fertilizado com $30 \mathrm{mg} \mathrm{dm}^{-3}$ de $\mathrm{N}$ (ureia), 250 $\mathrm{mg} \mathrm{dm}{ }^{-3}$ de $\mathrm{P}$ (superfosfato simples), $80 \mathrm{mg} \mathrm{dm}^{-3}$ de $\mathrm{K}$ (cloreto de potássio), $2 \mathrm{mg} \mathrm{dm}^{-3}$ de $\mathrm{Cu}$ (sulfato de cobre), $2 \mathrm{mg} \mathrm{dm}^{-3}$ de $\mathrm{Zn}$ (sulfato de zinco) e $1 \mathrm{mg} \mathrm{dm}^{-3}$ de $\mathrm{B}$ (ácido bórico), seguindo as recomendações de Novais et al. (1991) para ensaios de vaso em condições controladas.

O delineamento experimental utilizado foi o de blocos ao acaso em esquema fatorial $3 \times 4$ com quatro repetições. Os tratamentos foram constituídos por três tamanho de sementes (pequena, média e grande) e por quatro tratamentos de inoculação das sementes [i) controle (sem inoculação); ii) inoculação com Bradyrhizobium japonicum; iii) inoculação com Azospirillum brasilense; e, iv) coinoculação com $B$. japonicum e A. brasilense].

Sementes de amendoim (Arachis hypogaea L., cv. IAC Tatu ST), oriundas de um experimento de campo instalado no município de Cassilândia-MS, durante a safra de 2015/2016, foram separadas em três classes de tamanho a partir das diferenças de massa, definindo-se os seguintes grupos: i) Sementes pequenas (P), massa variando de 0,16-0,24 g; ii) Sementes médias (M), massa variando de 0,32-0,40 g; e, iii) Sementes grandes (G), massa variando de $0,48-0,56 \mathrm{~g}$.

A inoculação das sementes com Bradyrhizobium japonicum foi realizada com o inoculante comercial líquido Simbiose Nod Soja ${ }^{\circledR}$ (Simbiose: Agrotecnologia Biológica) contendo as estirpes SEMIA 5079 e SEMIA 5080 (concentração mínima de 7,2 x $10^{9}$ células viáveis por $\mathrm{mL}$ ), na dose de $150 \mathrm{~mL}$ para $50 \mathrm{~kg}$ de sementes. Para a inoculação com Azospirillum brasilense foi utilizado o inoculante comercial líquido AzoTotal ${ }^{\circledR}$
(Total Biotecnologia) que contém as estirpes AbV5 e AbV6 (concentração mínima de 2,0 x $10^{8}$ células viáveis por $\mathrm{mL}$ ), na dose de $200 \mathrm{~mL}$ para $50 \mathrm{~kg}$ de sementes. A coinoculação foi realizada misturando as duas rizobactérias, nas mesmas proporções utilizadas quando inoculadas isoladamente, ou seja, $150 \mathrm{~mL}$ do inoculante contendo B. japonicum $+200 \mathrm{~mL}$ de inoculante contendo $A$. brasilense para $50 \mathrm{~kg}$ de sementes de amendoim. As quantidades de inoculantes utilizadas foram dissolvidas em uma solução contendo 2 $\mathrm{mL} / \mathrm{kg}$ de semente de aditivo para inoculante Protege ${ }^{\circledR}$ TS (Total Biotecnologia) e, então, ambos os produtos (inoculante + aditivo) foram aplicadas nas sementes. $\mathrm{O}$ aditivo para inoculante é constituído de metabólitos ativos de bactérias, complexo de açúcares e biopolímeros encapsulantes e tem a finalidade de melhorar a proteção e a viabilidade das bactérias sobre as sementes.

A semeadura foi realizada no dia 21/12/2016, utilizando-se o cultivar IAC Tatu ST de porte ereto, ciclo precoce de 90 a 100 dias, e peso médio de 100 grãos de 40-46 g. Foram semeadas 10 sementes por vaso, e aos nove dias após a semeadura, realizou-se o desbaste deixando-se duas plantas por vaso. O teor de água do solo foi monitorado diariamente e mantido próximo da capacidade de retenção de água com irrigações diárias pelo sistema de microaspersão.

A temperatura e a umidade relativa do ar foram monitoradas diariamente durante todo o período de experimento com o auxílio de um Data Logger modelo ITLOG-80 (Instrutemp Instrumentos de Medição Ltda, São Paulo, SP, BRA) instalado dentro da casa de vegetação. As condições ambientais durante a condução do experimento foram: temperaturas mínima e máxima do ar de 19,2 e $38,0{ }^{\circ} \mathrm{C}$, respectivamente, e umidade relativa média do ar de $76 \%( \pm 6 \%)$.

Durante a fase de estabelecimento das plantas, o número de plântulas emergidas foi mensurado diariamente até o $12^{\circ}$ dia após a semeadura, e com os valores contabilizados, foram calculados a porcentagem de emergência (\%), o índice de velocidade de emergência (IVE) e o tempo médio de emergência (TME).

O IVE foi calculado pelo somatório do número de plântulas emergidas a cada dia, dividido pelo número de dias decorridos entre a semeadura e a emergência, de acordo com a equação proposta por Maguire (1962): $\operatorname{IVE}=\left(\mathrm{E}_{1} / \mathrm{N}_{1}\right)+\left(\mathrm{E}_{2} / \mathrm{N}_{2}\right)+\left(\mathrm{E}_{3} / \mathrm{N}_{3}\right)+\ldots+\left(\mathrm{E}_{\mathrm{n}} / \mathrm{N}_{\mathrm{n}}\right)$, onde, IVE = índice de velocidade de emergência (plântulas $\left.\operatorname{dia}^{-1}\right) ; E_{1}, E_{2}, E_{3}, \ldots, E n=$ número de plântulas emergidas computadas na primeira, segunda, terceira e última contagem; e, $\mathrm{N}_{1}, \mathrm{~N}_{2}, \mathrm{~N}_{3}, \ldots, \mathrm{N}_{\mathrm{n}}=$ número de dias da semeadura à primeira, segunda, terceira e última contagem. 
O TME foi obtido através de contagens diárias das plântulas emergidas até a última contagem e calculado através da proposta por Labouriau (1983): TME $=\Sigma$ $\left(\mathrm{n}_{\mathrm{i}} \mathrm{t}_{\mathrm{i}}\right) / \Sigma \mathrm{n}_{\mathrm{i}}$, onde, TME = tempo médio de emergência (dias); $\mathrm{n}_{\mathrm{i}}=$ número de plântulas emergidas no intervalo entre cada contagem; e, $\mathrm{t}_{\mathrm{i}}=$ tempo decorrido entre $\mathrm{o}$ início da emergência e a i-ésima contagem.

Aos 40 dias após a semeadura, no início do florescimento do amendoim, as plantas foram colhidas e as seguintes variáveis mensuradas: número de folhas (NF), contando-se todas as folhas desenvolvidas presentes na planta; número de hastes por planta $(\mathrm{NH})$, contando-se o número total de hastes das plantas; altura de planta (AP), medindo-se a haste principal do colo até o meristema apical com o auxílio de régua graduada em centímetro $(\mathrm{cm})$; número de nódulos $(\mathrm{NN})$, obtido pela contagem do número de nódulos presentes nas raízes. Em seguida, os nódulos foram destacados e colocados em estufa por 48 horas à $65{ }^{\circ} \mathrm{C}$ com pesagem do material seco em balança analítica com precisão de 0,0001 g e, então, calculado a razão entre a massa de matéria seca dos nódulos e o número de nódulos para obter-se a massa de matéria seca média por nódulo.

O volume radicular (VR) foi determinado pelo método de deslocamento de água, utilizando uma proveta de $100 \mathrm{~mL}$ graduada em mililitros (mL), portanto, com precisão de $\pm 1,0 \mathrm{~cm}^{3}$. A área foliar (AF) foi determinada seguindo metodologia proposta por Benincasa (2003), com modificações. Após a separação de todas as folhas das plantas, foram retirados 10 discos foliares de área conhecida $\left(2,0 \quad \mathrm{~cm}^{2}\right)$, que foi considerada a área foliar da amostra $\left(\mathrm{AF}_{\mathrm{Amostra}}\right)$. Em seguida, após a secagem em estufa de circulação forçada de ar, à temperatura de $65^{\circ} \mathrm{C}$, até atingirem massa constante, foi determinada a massa seca da amostra $\left(\mathrm{MS}_{\mathrm{Amostra}}\right)$ e a massa de matéria seca das folhas (MSF). A área foliar total (AF) foi obtida através da seguinte equação: $\mathrm{AF}=\left[\left(\mathrm{AF}_{\text {Amostra }} \times \mathrm{MSF}\right) / \mathrm{MS}_{\mathrm{Amostra}}\right]$.

Para a mensuração da massa de matéria seca das folhas (MSF), do caule (MSC), da parte aérea (MSPA), das raízes (MSR), as plantas foram seccionadas em folha, caule e raiz e, em seguida, acondicionadas em sacos de papel, colocadas para secar em estufa de circulação de ar forçada com temperatura de $65{ }^{\circ} \mathrm{C}$ até obter massa constante e, posteriormente, pesadas em balança analítica com precisão de $0,0001 \mathrm{~g}$, sendo os resultados expressos em g/planta; a massa seca da parte aérea foi obtida com a soma da massa seca das folhas com a massa seca do caule, e a massa seca total foi obtido com a somatória de todas as partes da planta (folhas, caule e raízes). A relação entre a matéria seca das raízes e da parte aérea (MSR/MSPA), obtida através da divisão da massa seca da parte aérea pela massa seca das raízes.
A razão de área foliar (RAF), área foliar específica (AFE) e a razão de massa das folhas (RMF) foram determinadas a partir dos valores de área foliar (AF) expressos em $\mathrm{dm}^{2} /$ planta, massa de matéria seca total da planta (MST) e matéria seca das folhas (MSF), ambos expressos em g/planta, empregando-se as seguintes equações, de acordo com Benincasa (2003): [RAF = AF / MST], [AFE = AF / MSF ] e [RMF = MSF / MST].

Os dados coletados para as diferentes variáveis foram previamente testados quanto à normalidade pelo teste de Kolmogorov-Smirnov à 5\% de significância, e então, submetidos à análise de variância e os efeitos significativos do teste $\mathrm{F}(\mathrm{p}<0,05)$ foram comparados pelo teste $\mathrm{t}$ (LSD), a $5 \%$ de probabilidade. Todas as análises foram realizadas utilizando-se o software estatístico Sisvar versão 5.3 para Windows (Software de Análises Estatísticas, UFLA, Lavras, MG, BRA).

\section{Resultados e Discussão}

\section{Emergência das plântulas de amendoim}

O tamanho das sementes de amendoim influenciou significativamente $(p<0,05)$ o tempo médio de emergência das plântulas, mas não interferiu de forma significativa na porcentagem de emergência e no índice de velocidade de emergência das plântulas (Tabela 1). O menor tempo de emergência das plântulas foi obtido com o uso de sementes médias e grandes, enquanto que as sementes pequenas resultaram no maior tempo médio para a emergência das plântulas (Tabela 2). Resultados contrários foram reportados por Queiroga et al. (2011), os quais avaliando o efeito do tamanho da semente de amendoim na qualidade fisiológica, verificaram que as sementes sem classificação (granel), e as sementes pequenas $(0,25$ a $0,43 \mathrm{~g})$ apresentaram os maiores valores nos testes de vigor e de germinação em comparação as sementes grandes $(0,47$ a $0,58 \mathrm{~g})$.

A inoculação das sementes com Bradyrhizobium japonicum e Azospirillum brasilense de forma isolada ou combinada não afetou significativamente $(\mathrm{p}>0,05)$ a porcentagem de emergência, o índice de velocidade de emergência e o tempo médio de emergência das plântulas de amendoim (Tabela 1). Estes resultados indicam que a inoculação de bactérias simbióticas e associativas nas sementes não comprometeu o estabelecimento inicial do estande de plantas. O estabelecimento de um estande adequado de plantas é fundamental para obter altos níveis de rendimentos de grãos de amendoim.

\section{Nodulação radicular do amendoim}

O tamanho das sementes e a inoculação com $B$. japonicum e $A$. brasilense de forma isolada ou combinada influenciou significativamente $(\mathrm{p}<0,05)$ o número de nódulos por planta, a matéria seca dos 
nódulos por planta e a matéria seca média por nódulo (Tabela 2).

Os maiores valores de número de nódulos por planta, matéria seca dos nódulos e matéria seca média por nódulo foram obtidos para as sementes grandes em comparação as sementes pequenas (Tabela 2). Estes resultados evidenciam que o tamanho das sementes exerce influência direta na formação e no tamanho dos nódulos das raízes de amendoim; sendo que as sementes grandes resultam em plantas com maior quantidade de nódulos, além de aumentar o tamanho dos nódulos em comparação as plantas oriundas de sementes pequenas (Tabela 2). Portanto, o uso de sementes de amendoim grande pode ser um fator determinante para o melhorar a formação e o tamanho dos nódulos radiculares das plantas de amendoim em solos arenosos do Cerrado. A coinoculação das sementes com $B$. japonicum e $A$. brasilense resultou no aumento de $80 \%$ no número de nódulos por planta, de $122 \%$ na matéria seca de nódulos por planta e de $28 \%$ na matéria seca média por nódulo em comparação ao tratamento controle (sem inoculação) (Tabela 2).

Tabela 1. Efeito do tamanho das sementes e do tratamento de inoculação com Bradyrhizobium japonicum e/ou Azospirillum brasilense na porcentagem de emergência, no índice de velocidade de emergência e no tempo médio de emergência das plântulas de amendoim (Arachis hypogaea L., cv. IAC Tatu ST) em um solo arenoso do Cerrado sob condições de casa de vegetação

\begin{tabular}{|c|c|c|c|}
\hline Fatores de variação & Emergência (\%) & $\begin{array}{l}\text { Índice de velocidade de } \\
\text { emergência (plântulas dia }{ }^{-1} \text { ) }\end{array}$ & $\begin{array}{l}\text { Tempo médio de } \\
\text { emergência(dias) }\end{array}$ \\
\hline \multicolumn{4}{|l|}{ Tamanho de semente } \\
\hline Pequena & $88,1 \mathrm{a}$ & $1,68 \mathrm{a}$ & $5,37 \mathrm{~b}$ \\
\hline Média & $94,4 \mathrm{a}$ & $1,85 \mathrm{a}$ & $5,16 \mathrm{a}$ \\
\hline Grande & $90,6 \mathrm{a}$ & $1,78 \mathrm{a}$ & $5,14 \mathrm{a}$ \\
\hline \multicolumn{4}{|l|}{ Tratamento de inoculação } \\
\hline Controle & 90,0 a & $1,74 \mathrm{a}$ & $5,28 \mathrm{a}$ \\
\hline Bradyrhizobium japonicum & $92,5 \mathrm{a}$ & $1,82 \mathrm{a}$ & $5,12 \mathrm{a}$ \\
\hline Azospirillum brasilense & $89,2 \mathrm{a}$ & $1,73 \mathrm{a}$ & $5,26 \mathrm{a}$ \\
\hline B. japonicum + A. brasilense & $92,5 \mathrm{a}$ & $1,80 \mathrm{a}$ & $5,22 \mathrm{a}$ \\
\hline Teste F & & Valor de F & \\
\hline Tamanho de semente $(\mathrm{T})$ & $1,46^{\mathrm{NS}}$ & $2,51^{\mathrm{NS}}$ & $4,73 *$ \\
\hline Inoculação (I) & $0,34^{\mathrm{NS}}$ & $0,60^{\mathrm{NS}}$ & $1,08^{\mathrm{NS}}$ \\
\hline Interação $(\mathrm{T} \times \mathrm{I})$ & $0,88^{\mathrm{NS}}$ & $0,86^{\mathrm{NS}}$ & $0,69^{\mathrm{NS}}$ \\
\hline $\mathrm{CV}(\%)$ & 5,82 & 4,65 & 4,55 \\
\hline
\end{tabular}

Médias seguidas da mesma letra, na coluna, para cada fonte de variação não diferem estatisticamente entre si pelo teste t (LSD) ao nível de 5\% de

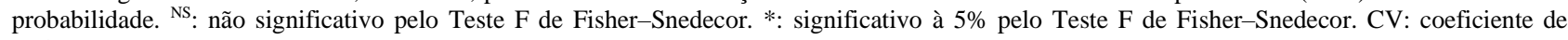
variação.

Tabela 2. Efeito do tamanho das sementes e do tratamento de inoculação com Bradyrhizobium japonicum e/ou Azospirillum brasilense no número de nódulos, na matéria seca dos nódulos e matéria seca média por nódulo das plantas de amendoim (Arachis hypogaea L., cv. IAC Tatu ST) cultivadas em um solo arenoso do Cerrado sob condições de casa de vegetação

\begin{tabular}{|c|c|c|c|}
\hline Fatores de variação & $\begin{array}{l}\text { Nódulos por planta } \\
\qquad\left(\mathrm{n}^{\mathrm{o}} .\right)\end{array}$ & $\begin{array}{c}\text { Matéria seca dos } \\
\text { nódulos } \\
\text { (mg/planta) }\end{array}$ & $\begin{array}{c}\text { Matéria seca média por } \\
\text { nódulo } \\
\text { (mg/nódulo) }\end{array}$ \\
\hline \multicolumn{4}{|l|}{ Tamanho de semente } \\
\hline Pequena & $46,3 \mathrm{~b}$ & $12,1 \mathrm{c}$ & $0,272 b$ \\
\hline Média & $58,3 \mathrm{~b}$ & $20,6 \mathrm{~b}$ & $0,391 \mathrm{a}$ \\
\hline Grande & $80,8 \mathrm{a}$ & $31,8 \mathrm{a}$ & $0,422 \mathrm{a}$ \\
\hline \multicolumn{4}{|l|}{ Tratamento de inoculação } \\
\hline Controle & $50,4 \mathrm{~b}$ & $14,9 \mathrm{c}$ & $0,323 \mathrm{~b}$ \\
\hline Bradyrhizobium japonicum & $58,3 \mathrm{~b}$ & $18,9 \mathrm{~b}$ & $0,328 \mathrm{~b}$ \\
\hline Azospirillum brasilense & $47,5 \mathrm{~b}$ & $19,1 \mathrm{~b}$ & $0,382 \mathrm{ab}$ \\
\hline B. japonicum + A. brasilense & $91,0 \mathrm{a}$ & $33,1 \mathrm{a}$ & $0,414 \mathrm{a}$ \\
\hline Teste F & & Valor de F & \\
\hline Tamanho de semente (T) & $7,85^{* *}$ & $57,26 * *$ & $11,08 * *$ \\
\hline Inoculação (I) & $7,06 * *$ & $22,81 * *$ & $2,75^{*}$ \\
\hline Interação $(\mathrm{T} \times \mathrm{I})$ & $2,25^{\mathrm{NS}}$ & $2,05^{\mathrm{NS}}$ & $2,27^{\mathrm{NS}}$ \\
\hline $\mathrm{CV}(\%)$ & 18,50 & 11,98 & 5,54 \\
\hline
\end{tabular}

Médias seguidas da mesma letra, na coluna, para cada fonte de variação não diferem estatisticamente entre si pelo teste t (LSD) ao nível de 5\% de probabilidade. ${ }^{N S}$ : não significativo pelo Teste $\mathrm{F}$ de Fisher-Snedecor. * e **: significativo à $5 \%$ e $1 \%$, respectivamente, pelo Teste $\mathrm{F}$ de FisherSnedecor. CV: coeficiente de variação. 
O aumento na quantidade e no tamanho dos nódulos por planta obtido com a coinoculação das sementes com B. japonicum e A. brasilense pode ter sido devido ao efeito sinergístico destas duas rizobactérias em melhorar a capacidade da formação dos nódulos radiculares em plantas leguminosas. Resultados semelhantes foram reportados por Santos et al. (2017), os quais concluíram que a coinoculação das sementes de amendoim com $B$. japonicum e $A$. brasilense pode proporcionar sustentabilidade para o sistema de produção de amendoim na região do Cerrado por melhorar a nodulação das raízes e a fixação biológica de nitrogênio.

Os efeitos benéficos da associação de bactérias simbióticas do gênero Bradyrhizobium com as bactérias associativas do gênero Azospirillum em plantas leguminosas se devem, na maior parte, à capacidade destas rizobactérias em fixar $\mathrm{N}_{2}$ atmosférico, produzir hormônios vegetais, aumentar a atividade da enzima nitrato redutase e solubilizar fosfato do solo (BOTTINI et al., 1989; CASSÁN et al., 2008; HUERGO et al., 2008; INAGAKI et al., 2014).

Santos et al. (2014) avaliando o efeito da inoculação de diferentes estirpes de rizóbio no crescimento inicial do amendoim cv. IAC Tatu ST, verificaram que a inoculação das sementes resultou no aumento do número de nódulos e na matéria seca de nódulos por planta. Por sua vez, Santos et al. (2005) avaliando diferentes isolados de rizóbios nativos da região nordeste do Brasil, verificaram que a quantidade e o tamanho dos nódulos por planta foram muito dependentes do cultivar e do isolado utilizado. A cultura do amendoim pode estabelecer simbiose com várias estirpes do gênero Rhizobium sp. e Bradyrhizobium sp. No entanto, para aumentar a eficiência da inoculação é de fundamental importância que as estirpes do inoculante tenha elevada capacidade de competir com as estirpes nativas de rizóbios do solo.

A inoculação das sementes com $B$. japonicum e $A$. brasilense de forma isolada não se mostrou uma prática agronômica eficiente, por resultar em capacidade de nodulação semelhante ao tratamento controle (sem inoculação) (Tabela 2). Resultados semelhantes foram reportados por Veronezi et al. (2012), os quais avaliando diferentes estirpes de Rhizobium sp. e A. brasilense na cultura do feijoeiro, verificaram que a coinoculação das sementes com o isolado CPAO 19.5 L3 em associação as estirpes Ab-V5 e Ab-V6 de A. brasilense resultou em maior nodulação radicular das plantas em comparação as sementes inoculadas com estas estirpes de isolada. De modo similar, Silva et al. (2016) também verificaram que a inoculação com Bradyrhizobium sp. não exerceu efeito significativo para o aumento no número de nódulos das plantas de amendoim. Tal inferência pode estar relacionada com a capacidade da cultura do amendoim em estabelecer associações simbióticas com uma ampla gama de rizóbios nativos do solo, como reportado por Borges et al. (2007).

Crescimento e produção de matéria seca das plantas

$\mathrm{O}$ tamanho das sementes afetou significativamente ( $\mathrm{p}<0,05)$ o número de folhas por planta, o número de hastes por planta, a altura das plantas, a área foliar, o volume radicular e a produção de matéria seca da parte aérea, das raízes e total das plantas de amendoim (Tabelas 3 e 4). A maior taxa de crescimento e acúmulo de matéria seca das plantas de amendoim foi obtida quando se utilizou sementes grandes, ao passo que as sementes pequenas originaram plantas de amendoim menores e com menor acúmulo de matéria seca. Estes resultados reportam que a quantidade de reserva das sementes utilizadas na semeadura exerce efeito direto no crescimento e desenvolvimento inicial das plantas de amendoim. Sementes grandes com maior quantidade de reserva podem resultar em plantas com maior taxa de crescimento inicial e maior acúmulo de matéria seca da parte aérea e das raízes (Tabelas 3 e 4).

Avaliando a influência do tamanho das sementes na qualidade fisiológica e na produtividade da cultura da soja, Pádua et al. (2010) afirmaram que as plantas originadas de sementes menores, possuem menor altura durante a colheita e, consequentemente, resultam em menor produtividade de grãos. Tal afirmação corrobora com os resultados apresentados neste estudo, sendo que as plantas de amendoim oriundas de sementes pequenas possuíram a menor altura, menor área foliar e menor acúmulo de matéria seca da parte aérea e das raízes.

Existe grande associação do tamanho da semente, com a sua reserva nutritiva, indicando que sementes maiores, apresentam maior quantidade de tecido de reserva energética. Conforme Carvalho e Nakagawa (2000), a quantidade de reserva da semente influência no vigor e no crescimento inicial da planta, originando plântulas mais nutridas, por fornecer dessa forma, maior nutrição à plântula, como reportado neste estudo.

A inoculação das sementes com B. japonicum e $A$. brasilense de forma isolada ou combinada influenciou significativamente $(p<0,05)$ a altura e a matéria seca total das plantas, mas não interferiu de forma significativa ( $\mathrm{p}>0,05$ ) no número de folhas por planta, número de hastes por planta, área foliar, volume radicular, matéria seca da parte aérea e das raízes e relação raiz: parte aérea das plantas de amendoim (Tabelas 3 e 4). Estes resultados indicam que a inoculação de bactérias simbióticas e associativas nas sementes de amendoim tem pouco efeito no crescimento e desenvolvimento inicial das plantas quando cultivadas em condições controladas. 
Tabela 3. Efeito do tamanho das sementes e do tratamento de inoculação com Bradyrhizobium japonicum e/ou Azospirillum brasilense no número de folhas por planta, número de hastes por planta, altura de planta, área foliar e volume radicular das plantas de amendoim (Arachis hypogaea L., cv. IAC Tatu ST) cultivadas em um solo arenoso do Cerrado sob condições de casa de vegetação

\begin{tabular}{|c|c|c|c|c|c|}
\hline Fatores de variação & $\begin{array}{c}\text { Folhas por planta } \\
\left(\mathrm{n}^{\circ} .\right)\end{array}$ & $\begin{array}{l}\text { Haste por planta } \\
\left(\mathrm{n}^{\circ} .\right)\end{array}$ & $\begin{array}{l}\text { Altura de planta } \\
(\mathrm{cm})\end{array}$ & $\begin{array}{c}\begin{array}{c}\text { Área foliar } \\
\left(\mathrm{dm}^{2} / \text { planta }\right)\end{array} \\
\end{array}$ & $\begin{array}{c}\text { Volume radicular } \\
\left(\mathrm{cm}^{3} / \text { planta }\right)\end{array}$ \\
\hline \multicolumn{6}{|l|}{ Tamanho de semente } \\
\hline Pequena & $21,7 \mathrm{~b}$ & $3,41 \mathrm{~b}$ & $8,87 \mathrm{c}$ & $0,24 \mathrm{c}$ & $12,0 \mathrm{c}$ \\
\hline Média & $24,7 \mathrm{a}$ & $4,00 \mathrm{a}$ & $10,40 \mathrm{~b}$ & $0,31 \mathrm{~b}$ & $16,7 \mathrm{~b}$ \\
\hline Grande & $26,5 \mathrm{a}$ & $3,91 \mathrm{a}$ & $11,69 \mathrm{a}$ & $0,39 \mathrm{a}$ & $21,6 \mathrm{a}$ \\
\hline \multicolumn{6}{|l|}{ Tratamento de inoculação } \\
\hline Controle & $23,8 \mathrm{a}$ & $3,63 \mathrm{a}$ & $9,75 \mathrm{~b}$ & $0,30 \mathrm{a}$ & $15,8 \mathrm{a}$ \\
\hline Bradyrhizobium japonicum & $24,3 \mathrm{a}$ & $3,79 \mathrm{a}$ & $10,62 \mathrm{ab}$ & $0,32 \mathrm{a}$ & $17,1 \mathrm{a}$ \\
\hline Azospirillum brasilense & $23,6 \mathrm{a}$ & $3,71 \mathrm{a}$ & $9,92 \mathrm{ab}$ & $0,31 \mathrm{a}$ & $16,6 \mathrm{a}$ \\
\hline B. japonicum + A. brasilense & $25,3 \mathrm{a}$ & $3,96 \mathrm{a}$ & $11,00 \mathrm{a}$ & $0,31 \mathrm{a}$ & $17,6 \mathrm{a}$ \\
\hline Teste F & & & Valor de F & & \\
\hline Tamanho de semente (T) & $12,72 * *$ & $5,15^{*}$ & $14,61 * *$ & $68,46 * *$ & $55,53 * *$ \\
\hline Inoculação (I) & $0,95^{\mathrm{NS}}$ & $0,71^{\mathrm{NS}}$ & $2,85^{*}$ & $0,56^{\mathrm{NS}}$ & $1,05^{\mathrm{NS}}$ \\
\hline Interação $(\mathrm{T} \times \mathrm{I})$ & $2,30^{\mathrm{NS}}$ & $0,38^{\mathrm{NS}}$ & $1,06^{\mathrm{NS}}$ & $2,38^{\mathrm{NS}}$ & $0,76^{\mathrm{NS}}$ \\
\hline $\mathrm{CV}(\%)$ & 5,60 & 6,60 & 6,88 & 7,61 & 7,62 \\
\hline
\end{tabular}

Médias seguidas da mesma letra, na coluna, para cada fonte de variação não diferem estatisticamente entre si pelo teste t (LSD) ao nível de 5\% de probabilidade. ${ }^{N S}$ : não significativo pelo Teste $\mathrm{F}$ de Fisher-Snedecor. * e **: significativo à $5 \%$ e $1 \%$, respectivamente, pelo Teste $\mathrm{F}$ de FisherSnedecor. CV: coeficiente de variação.

Tabela 4. Efeito do tamanho das sementes e do tratamento de inoculação com Bradyrhizobium japonicum e/ou Azospirillum brasilense na matéria seca da parte aérea, matéria seca das raízes, matéria seca total e relação raiz: parte aérea das plantas de amendoim (Arachis hypogaea L., cv. IAC Tatu ST) cultivadas em um solo arenoso do Cerrado sob condições de casa de vegetação

\begin{tabular}{|c|c|c|c|c|}
\hline Fatores de variação & $\begin{array}{c}\text { Matéria seca da parte } \\
\text { aérea } \\
\text { (g/planta) }\end{array}$ & $\begin{array}{c}\text { Matéria seca das } \\
\text { raízes } \\
\text { (g/planta) }\end{array}$ & $\begin{array}{c}\text { Matéria seca total } \\
\text { (g/planta) }\end{array}$ & $\begin{array}{c}\text { Relação raiz: parte } \\
\text { aérea } \\
\left(\mathrm{g} \mathrm{g}^{-1}\right)\end{array}$ \\
\hline \multicolumn{5}{|l|}{ Tamanho de semente } \\
\hline Pequena & $1,68 \mathrm{c}$ & $0,98 \mathrm{c}$ & $2,66 \mathrm{c}$ & $0,59 \mathrm{a}$ \\
\hline Média & $2,50 \mathrm{~b}$ & $1,45 \mathrm{~b}$ & $3,95 \mathrm{~b}$ & $0,59 \mathrm{a}$ \\
\hline Grande & $3,13 \mathrm{a}$ & $1,71 \mathrm{a}$ & $4,83 \mathrm{a}$ & $0,55 \mathrm{a}$ \\
\hline \multicolumn{5}{|l|}{ Tratamento de inoculação } \\
\hline Controle & $2,32 \mathrm{a}$ & $1,33 \mathrm{a}$ & $3,65 \mathrm{~b}$ & $0,57 \mathrm{a}$ \\
\hline Bradyrhizobium japonicum & $2,48 \mathrm{a}$ & $1,43 \mathrm{a}$ & $3,91 \mathrm{a}$ & $0,58 \mathrm{a}$ \\
\hline Azospirillum brasilense & $2,40 \mathrm{a}$ & $1,34 \mathrm{a}$ & $3,74 \mathrm{ab}$ & $0,58 \mathrm{a}$ \\
\hline B. japonicum + A. brasilense & $2,54 \mathrm{a}$ & $1,41 \mathrm{a}$ & $3,95 \mathrm{a}$ & $0,57 \mathrm{a}$ \\
\hline Teste F & \multicolumn{4}{|c|}{ Valor de F } \\
\hline Tamanho de semente $(\mathrm{T})$ & $120,10 * *$ & $124,18 * *$ & $212,98 * *$ & $1,00^{\mathrm{NS}}$ \\
\hline Inoculação (I) & $1,63^{\mathrm{NS}}$ & $1,67^{\mathrm{NS}}$ & $2,88^{*}$ & $0,06^{\mathrm{NS}}$ \\
\hline Interação $(T \times I)$ & $2,38^{\mathrm{NS}}$ & $2,32^{\mathrm{NS}}$ & $2,29^{\mathrm{NS}}$ & $0,75^{\mathrm{NS}}$ \\
\hline $\mathrm{CV}(\%)$ & 10,35 & 9,61 & 7,85 & 6,45 \\
\hline
\end{tabular}

Médias seguidas da mesma letra, na coluna, para cada fonte de variação não diferem estatisticamente entre si pelo teste t (LSD) ao nível de 5\% de probabilidade. Ns. não significativo pelo Teste $\mathrm{F}$ de Fisher-Snedecor. * e **: significativo à $5 \%$ e $1 \%$, respectivamente, pelo Teste $\mathrm{F}$ de FisherSnedecor. CV: coeficiente de variação.

No entanto, a coinoculação das sementes com as duas rizobactérias resultou em plantas com maior altura em comparação ao tratamento controle (sem inoculação), indicando que a inoculação combinada de B. japonicum e A. brasilense melhorou a taxa de crescimento das plantas de amendoim (Tabela 3).

$\mathrm{O}$ aumento do crescimento das plantas de amendoim com a coinoculação das sementes pode estar relacionado aos benefícios oriundos da coinoculação, por meio da associação da capacidade de fixação de $\mathrm{N}_{2}$ pelas bactérias com $B$. japonicum com a produção de hormônios vegetais das bactérias A. brasilense. Segundo Bárbaro et al. (2009), a coinoculação consiste na utilização de combinações de diferentes microorganismos, aos quais produzem um efeito sinérgico, em que quando utilizados em combinação superam os resultados produtivos obtidos com os mesmos, quando em forma isolada. Cabe salientar, que entre os hormônios vegetais, as estirpes de A. brasilense têm capacidade de produzir auxinas, giberelinas, citocininas em condições "in vitro" (MASCIARELLI et al., 2013). 
A inoculação das sementes com $B$. japonicum e $A$. brasilense de forma isolada e combinada não afetou significativamente $(\mathrm{p}>0,05)$ o desenvolvimento do sistema radicular das plantas de amendoim, como evidenciado para o volume radicular (Tabela 3) e matéria secas das raízes e relação raiz: parte aérea (Tabela 4). Estes resultados indicam que a inoculação de bactérias simbióticas e associativas não interfere no crescimento das raízes de amendoim em condições controladas. Resultados semelhantes foram reportados por Zuffo et al. (2015), os quais avaliaram a inoculação de A. brasilense isoladamente ou em coinoculação com B. japonicum na cultura da soja, e verificaram que não houve efeito significativo da inoculação na matéria seca das raízes, matéria seca dos nódulos e no volume radicular.

\section{Índices morfofisiológicos das plantas de amendoim}

Os valores dos índices morfofisiológicos das plantas de amendoim aos 40 dias após a semeadura em função do tamanho da semente e da inoculação com $B$. japonicum e $A$. brasilense de forma isolada ou combinada são mostrados na Tabela 5. O tamanho da semente afetou significativamente $(\mathrm{p}<0,05)$ a razão de área foliar (RAF) e a área foliar especifica (AFE), mas não interferiu de na razão de massa das folhas (RMF) de amendoim (Tabelas 5). Por sua vez, a coinoculação com $B$. japonicum e $A$. brasilense de forma combinada não influenciou significativamente $(\mathrm{p}>0,05)$ nenhum dos índices morfofisiológicos da planta de amendoim (Tabela 5).

A razão de área foliar (RAF) representa a área foliar total $\left(\mathrm{em} \mathrm{dm}^{2}\right)$ que está sendo usada pela planta para produzir 1,0 g de matéria seca (BENINCASA, 2003). Portanto, este índice expressa a area foliar útil para a fotossíntese. O aumento da RAF com a utilização de sementes pequenas indica que houve maior conversão dos fotoassimilados em folhas em relação as demais órgãos das plantas, como caule e raiz. Por outro lado, os menores valores com a utilização de sementes médias e grandes são decorrentes da maior taxa de conversão dos fotoassimilados em caule e raízes em detrimento de folhas, além do maior auto-sombreamento e queda de folhas com o maior crescimento e desenvolvimento das plantas nestes tratamentos.

A área foliar específica (AFE) relaciona a superfície e a massa da folha, representando a espessura desta. Portanto, considerando que a AFE representa o espessamento da folha (BENINCASA, 2003), a redução do índice indica o acúmulo de fotoassimilados pelas folhas (folhas mais espessas) para posterior translocação a outros órgãos da planta. Os resultados aqui apresentados indicam que a utilização de sementes médias e grandes resultam na maior espessura das folhas de amendoim em comparação ao uso de sementes pequenas (Tabela 5).

A razão de massa das folhas (RMF) expressa a fração de massa de matéria seca não exportada das folhas para os demais órgãos da planta (BENINCASA, 2003). Portanto, constitui um importante indicador fisiológico da planta em virtude de mais de $90 \%$ dos fotoassimilados serem produzidos nas folhas, e a partir daí translocados para os demais órgãos da planta.

Tabela 5. Efeito do tamanho das sementes e do tratamento de inoculação com Bradyrhizobium japonicum e/ou Azospirillum brasilense na razão de área foliar (RAF), na área foliar específica (AFE) e na razão de massa das folhas (RMF) das plantas de amendoim (Arachis hypogaea L., cv. IAC Tatu ST) cultivadas em um solo arenoso do Cerrado sob condições de casa de vegetação

\begin{tabular}{|c|c|c|c|}
\hline Fatores de variação & $\begin{array}{c}\text { Razão de área foliar } \\
\left(\mathrm{dm}^{2} \mathrm{~g}^{-1}\right)\end{array}$ & $\begin{array}{l}\text { Área foliar específica } \\
\left(\mathrm{dm}^{2} \mathrm{~g}^{-1}\right)\end{array}$ & $\begin{array}{l}\text { Razão de massa das folhas } \\
\qquad\left(\mathrm{g} \mathrm{g}^{-1}\right)\end{array}$ \\
\hline \multicolumn{4}{|l|}{ Tamanho de semente } \\
\hline Pequena & $0,091 \mathrm{a}$ & $0,280 \mathrm{a}$ & $0,324 \mathrm{a}$ \\
\hline Média & $0,078 \mathrm{~b}$ & $0,253 \mathrm{~b}$ & $0,308 \mathrm{a}$ \\
\hline Grande & $0,081 \mathrm{~b}$ & $0,251 \mathrm{~b}$ & $0,323 \mathrm{a}$ \\
\hline \multicolumn{4}{|l|}{ Tratamento de inoculação } \\
\hline Controle & $0,085 \mathrm{a}$ & $0,264 \mathrm{a}$ & $0,323 \mathrm{a}$ \\
\hline Bradyrhizobium japonicum & $0,083 \mathrm{a}$ & $0,268 \mathrm{a}$ & $0,310 \mathrm{a}$ \\
\hline Azospirillum brasilense & $0,085 \mathrm{a}$ & $0,263 \mathrm{a}$ & $0,323 \mathrm{a}$ \\
\hline B. japonicum + A. brasilense & $0,079 \mathrm{a}$ & $0,250 \mathrm{a}$ & $0,317 \mathrm{a}$ \\
\hline Teste F & & Valor de F & \\
\hline Tamanho de semente $(\mathrm{T})$ & $9,70 * *$ & $8,04 * *$ & $1,50^{\mathrm{NS}}$ \\
\hline Inoculação (I) & $1,11^{\mathrm{NS}}$ & $1,37^{\mathrm{NS}}$ & $0,46^{\mathrm{NS}}$ \\
\hline Interação $(\mathrm{T} \times \mathrm{I})$ & $2,09^{\mathrm{NS}}$ & $1,26^{\mathrm{NS}}$ & $0,46^{\mathrm{NS}}$ \\
\hline $\mathrm{CV}(\%)$ & 10,57 & 8,89 & 9,51 \\
\hline
\end{tabular}

Médias seguidas da mesma letra, na coluna, para cada fonte de variação não diferem estatisticamente entre si pelo teste t (LSD) ao nível de 5\% de probabilidade. ${ }^{\text {NS: }}$ não significativo pelo Teste F de Fisher-Snedecor. **: significativo à $1 \%$ pelo Teste F de Fisher-Snedecor. CV: coeficiente de variação. 
Os resultados apresentados na Tabela 5 indicam que a translocação de matéria seca das folhas para os outros órgãos se manteve constante independentemente do tamanho da semente e da inoculação das sementes com B. japonicum e A. brasilense. A maior ou menor exportação de matéria seca da folha, pode ser uma característica genética a qual está sob a influência de variáveis ambientais. Contudo, são necessários mais estudos com a cultura do amendoim para verificar se esta característica é inerente da própria da espécie, ou se as condições climáticas foram as que proporcionaram essa característica do índice

\section{Conclusões}

A implantação da cultura do amendoim, sempre que possível, deve ser realizada com a utilização de sementes de maior tamanho (grandes), por melhorar a nodulação das raízes e promover o maior crescimento, desenvolvimento e acúmulo de matéria seca das plantas quando comparado a utilização de sementes menores (pequenas e médias). Portanto, o uso de sementes de amendoim grande pode ser um fator determinante para a sustentabilidade dos sistemas de produção e assegurar elevados níveis de produtividade para os solos arenosos do Cerrado Sul-mato-grossense.

A coinoculação das sementes com Bradyrhizobium japonicum e Azospirillum brasilense melhorou a nodulação das raízes e a altura das plantas, no entanto, não teve efeito no crescimento, na partição de matéria seca e nos índices morfofisiológicos das plantas de amendoim, quando cultivadas em solos arenosos do Cerrado sob condições controladas. Estes resultados indicam que novos estudos devem ser realizados para avaliar os efeitos benéficos da coinoculação de bactéria dos gêneros Bradyrhizobium e Azospirillum na cultura do amendoim.

\section{Referências Bibliográficas}

BÁRBARO, I. M.; MACHADO, P. C.; BÁRBARO-JUNIOR, L. S.; TICELli, M.; MIGUEL, F. B.; SILVA, J. A. A. Produtividade da soja em resposta à inoculação padrão e coinoculação. Colloquium Agrariae, Presidente Prudente-SP, v. 5, n. 1, p. 1-7, 2009.

BENINCASA, M. P. M. Análise de crescimento de plantas: noções básicas. Jaboticabal-SP: FUNEP, 2003, 41 p.

BORGES, W. L.; SILVA, C. E. R.; XAVIER, G. R.; RUMJANEK, N. G. Nodulação e fixação biológica de nitrogênio de acessos de amendoim com estirpes nativas de rizóbios. Revista Brasileira de Ciências Agrárias, RecifePE, v. 2, n. 1, p. 32-37, 2007.

BOTTINI, R.; FULCHIERI, M.; PEARCE, D.; PHARIS, R. Identification of gibberelins A1, A3, and iso-A3 in cultures of
A. lipoferum. Plant Physiology, Amsterdam, v. 90, p. 45-47, 1989.

CARVALHO, N. M. Efeitos do tamanho sobre o comportamento da semente de amendoim. Ciência e Cultura, São Paulo-SP, v. 24, n. 1, p. 64-69, 1972.

CARVALHO, N. M.; NAKAGAWA, J. Sementes: Ciência, Tecnologia e produção. 4. ed. Jaboticaba-SPl: FUNEP, 2000. $588 \mathrm{p}$.

CASSÁN, F.; SGROY, V.; PERRIG, D.; MASCIARELLI, O.; LUNA, V. Producción de fitohormonas por Azospirillum sp. Aspectos fisiológicos y tecnológicos de la promoción del crecimiento vegetal. In: CASSÁN, F. D.; SALAMONE, I. G. (Ed.) Azospirillum sp.: cell physiology, plant interactions and agronomic research in Argentina. Buenos Aires: Asociación Argentina de Microbiologia, 2008. p. 61-86.

CRUSCIOL, C. A. C.; SORATTO, R. P. Nutrição e produtividade do amendoim em sucessão ao cultivo de plantas de cobertura no sistema plantio direto. Pesquisa Agropecuária Brasileira, Brasília, v. 42, n. 6, p. 1-8, 2007.

DOBBELAERE, S.; VANDERLEYDEN, J.; OKON, Y. Plant growth-promoting effects of diazotrophs in the rhizosphere. Critical Reviews in Plant Sciences, Amsterdam, v. 22, n. 2, p. 107-149, 2003.

FAOSTAT. FOOD AND AGRICULTURE ORGANIZATION OF THE UNITED NATIONS. Food and agriculture statistic data. Disponível em: <http://www.fao.org/faostat/en/>. Acesso em: 23 jul. 2017.

GROTTA, D. C. C.; FURLANI, C. E. A.; SILVA, R. P.; REIS, G. N.; CORTEZ, J. W.; ALVES, P. J. Influência da profundidade de semeadura e da compactação do solo sobre a semente na produtividade do amendoim. Ciência e Agrotecnologia, Lavras-MG, v. 32, n. 2, p. 547-552, 2008.

HUERGO, L. F.; MONTEIRO, R. A.; BONATTO, A. C.; RIGO, L. U.; STEFFENS, M. B. R.; CRUZ, L. M.; CHUBATSU, L. S.; SOUZA, E. M.; PEDROSA, F. O. Regulation of nitrogen fixation in Azospirillum brasilense. In: CASSÁN, F. D.; GARCIA DE SALAMONE, I. Azospirillum sp.: cell physiology, plant interactions and agronomic research in Argentina. Buenos Aires: Asociación Argentina de Microbiologia, 2008. p. 17-35.

HUNGRIA, M.; NOGUEIRA, M. A. Efeitos da coinoculação. Cultivar Grandes Culturas, Pelotas-RS, v. 170, n. 1, p. 40-41, 2013.

HUNGRIA, M.; NOGUEIRA, M. A.; ARAUJO, R. S. Coinoculation of soybeans and common beans with rhizobia and azospirilla: strategies to improve sustainability. Biology Fertility of Soils, Amsterdam, v. 49, n. 7, p. 791-801, 2013.

INAGAKI, A. M.; GUIMARÃES, V. F.; RODRIGUES, L. F. O. S.; SILVA, M. B.; DIAMANTE, M. S.; RAMPIM, L.; MIORANZA, T. M.; DUARTE JÚNIOR, J. B. Phosphorus fertilization associated to inoculation of maize with diazotrophic bacteria. African Journal of Agricultural Research, Lagos, v. 9, n. 48, p. 3480-3487, 2014.

LABOURIAU, L. G. A germinação de sementes. Washington: Organização dos Estados Americanos, 1983. 174 p. 
MAGUIRE, J. D. Speed of germination - aid in selectionand evaluation for seedling emergence and vigor. Crop Science, Madson-USA, v. n. 1, p. 2:176-177, 1962.

MASCIARELLI, O.; URBANI, L.; REINOSO, H.; LUNA, V. Alternative Mechanism for the Evaluation of Indole-3-Acetic Acid (IAA) Production by Azospirillum brasilense Strains and Its Effects on the Germination and Growth of Maize Seedlings. Journal Microbiology, New York-USA, v. 51, n. 5, p. 590-597, 2013.

NOVAIS, R. F.; NEVES, J. C. L.; BARROS, N. F. Ensaio em ambiente controlado. In: OLIVEIRA, A. J.; GARRIDO, W. E.; ARAÚJO, J. D.; LOURENÇO, S. (Coord.). Métodos de pesquisa em fertilidade do solo. Brasília-DF: Embrapa-SEA, 1991. p. 189-253. (Documentos, 3).

PÁDUA, G. P.; ZITO, R. K.; ARANTES, N. E.; FRANÇA NETO, J. B. Influência do tamanho da semente na qualidade fisiológica e na produtividade da cultura da soja. Revista Brasileira de Sementes, Londrina-PR, v. 32, n. 3, p. 9-16, 2010.

QUEIROGA, V. P.; FREIRE, R. M. M.; ARAÚJO, M. E. R.; LIMA, V. I.; QUEIROGA, D. A. N. Influência do tamanho da semente de amendoim sobre sua qualidade fisiológica. Revista Agroambiente On-Line, Boa Vista-RO, v. 5, n. 1, p. 30-34, 2011.

SANTOS, C. C.; GUIMARÃES, S. L.; FARIAS, L. N.; BONFIM-SILVA, E. M.; POLIZEL, A. C. Crescimento inicial de plantas de amendoim inoculadas com rizóbio isolado de feijão caupi. Enciclopédia Biosfera: Centro Científico Conhecer, Goiânia-GO, v. 10, n. 18; p. 1097-1105, 2014.
SANTOS, C. E. R. S.; STAMFORD, N. P.; FREITAS, A. D. S. F.; VIEIRA, I. M. M. B.; SOUTO, S. M.; NEVES, M. C. P.; RUMJANEK, N. G. Efetividade de rizóbios isolados de solos da região Nordeste do Brasil na fixação do $\mathrm{N}_{2}$ em amendoim (Arachis hypogaea L.). Acta Scientiarum Agronomy, Maringá-PR, v. 27, n. 2, p. 301-307, 2005

SANTOS, D. M. S.; BUSH, A.; SILVA, E. R.; ZUFFO, A. M.; STEINER, F. Bactérias fixadoras de nitrogênio e molibdênio no cultivo do amendoim em solo do Cerrado. Revista de Agricultura Neotropical, Cassilândia-MS, v. 4, suplemento 1, p. 1-9, 2017.

SILVA, A. C.; CAVAlCANTE, A. C. P.; CAVAlCANTE, A. G.; DINIZ NETO, M. A. Bactérias fixadoras de nitrogênio e substratos orgânicos no crescimento e índices clorofiláticos de amendoim. Revista Agropecuária Técnica, Areia-PB, v. 37, n. 1, p. 1-8, 2016.

THIES, J. E.; SINGLETON, P. W.; BOHLOOL B. B. Influence of the size of indigenous rhizobial populations on establishment and symbiotic performance of introduced rhizobia on field-grown legumes. Applied and Environmental Microbiology, Amsterdam, v. 57, n. 1, p. 1928, 1991.

VERONEZI, S. D. F.; COSTA, M. R.; SILVA, A. T.; MERCANTE, F. M. Co-inoculação de rizóbio e Azospirillum brasilense em feijoeiro (Phaseolus vulgaris L.). Cadernos de Agroecologia, Curitiba-PR, v. 7, n. 2, 2012. 4 p.

ZUFFO, A. M.; REZENDE, P. M.; BRUZI, A. T.; OLIVEIRA, N. T.; SOARES, I. O.; NETO G. F. G.; CARDILlO, B. E. S.; SILVA, L. O. Co-inoculation of Bradyrhizobium japonicum and Azospirillum brasilense in the soybean crop. Revista de Ciências Agrarias, Lisboa, v. 38, n. 1, p. 87-93, 2015. 